\title{
ANÁLISE QUANTITATIVA DA RECEPTIVIDADE A PRESENÇA DE ABRIGOS DE MORCEGOS HEMATÓFAGOS Desmodus rotundus NO MUNICÍPIO DE SÃO PEDRO-SP
}

\author{
Paulo Jacques Mialhe ${ }^{1}$ \\ Luiz Eduardo Moschini ${ }^{2}$ \\ Fabíola Geovanna Piga ${ }^{3}$
}

\begin{abstract}
RESUMO
O morcego hematófago Desmodus rotundus é o principal transmissor da raiva dos herbívoros, responsável por enormes prejuízos econômicos na pecuária na América Latina. Devido às interações de $D$. rotundus com o meio ambiente, o risco da raiva nos herbívoros pode ser explicado pela vulnerabilidade e a receptividade do ambiente a capacidade do ecossistema albergar populações de D. rotundus. Utilizando de Sistema de Informações Geográficas foram analisados quantitativamente os seguintes determinantes de receptividade em que se encontravam os abrigos de morcegos hematófagos $D$. rotundus no município de São Pedro SP: tipo de solo e geologia, uso e cobertura do solo, declividade, hipsometria e proximidade a corpos de água. Foram localizados oito abrigos de D.rotundus, sendo dois abrigos naturais: uma gruta de arenito de Geologia Formação Piramboia e Neossolo Quartzarênico habitada por apenas um morcego, e outra gruta basáltica de Geologia Formação Itaqueri e Latossolo Vermelho-amarelo com uma população estimada de 100 D.rotundus. $75 \%$ dos abrigos estava em áreas de pastagem e cana de açúcar, seguido por áreas de vegetação nativa e vegetação riparia associada a pastagens. A presença de abrigos de D. rotundus em áreas de cultura canavieira e pastoril em quantidade superior a áreas de cobertura florestal ressalta a importância de oferta de abrigos artificiais em áreas agrícolas. A declividade do terreno em que se encontravam os abrigos variou de 3\% a 29\%. 62,5\% dos abrigos estavam em áreas com baixas declividades com presença de pastagens, porem próximos a áreas de relevo mais escarpado e vegetação nativa com altitudes que variaram entre $475 \mathrm{~m}$ e $929 \mathrm{~m}$. Todos os abrigos estavam localizados próximos a corpos d'agua. Apesar de corpos d'agua não constarem como fator de receptividade à presença de abrigos de D. rotundus no modelo epidemiológico indicado pelo Manual de Combate a Raiva dos Herbívoros - MAPA, no presente estudo a proximidade de todos os abrigos de $D$. rotundus a corpos d'agua evidencia a importância deste fator na receptividade ambiental à presença de abrigos destes morcegos, tornando relevante a inclusão deste fator nos modelos epidemiológicos de controle da raiva dos herbívoros. Desta forma faz-se necessária uma reavaliação da importância dos fatores de receptividade à presença de abrigos de $D$. rotundus nos modelos epidemiológicos, considerando a escala e particularidades de cada região em estudo, a inclusão outros tipos de formação geológica além da calcária para formação de abrigos naturais, a inclusão de novos tipos e cobertura de solo e a proximidade de corpos d'agua.
\end{abstract}

Palavras-chave: Desmodus rotundus, raiva, receptividade, abrigos

\footnotetext{
${ }^{1}$ Mestrando em Ecologia e Recursos Naturais. Universidade Federal de São Carlos. UFSCar. Correspondência: paulomialhe@gmail.com

2 Docente da Universidade Federal de São Carlos. lemoschini@ufscar.com.br

${ }^{3}$ Universidade Federal de São Carlos - UFSCar (sem vínculo empregatício) fabipiga@gmail.com
}

Mialhe PJ, Moschini LE, Piga FG. Análise quantitativa da receptividade a presença de abrigos de morcegos hematófagos Desmodus rotundus no Município de São Pedro-SP. Vet. e Zootec. 2022 ; v29: 001-015. 


\title{
QUANTITATIVE ANALYSIS OF THE RECEPTIVITY OF THE PRESENCE OF VAMPIRE BATS Desmodus rotundus SHELTERS IN THE MUNICIPALITY OF SÃO PEDRO-SP
}

\begin{abstract}
The vampire bat Desmodus rotundus is the main transmitter rabies in herbivores, responsible for enormous economic losses in livestock in Latin America. Due to interactions of $D$. rotundus with the environment, the risk of rabies in herbivores can be explained by the vulnerability and receptiveness of the environment to the capacity of the ecosystem to support populations of D. rotundus. Using a Geographic Information System, the following determinants of receptivity were quantitatively analyzed in which the vampire bat roosts $D$. rotundus were found in the city of São Pedro - SP: soil type and geology, land use and cover, slope, hypsometry and proximity to water bodies. Eight $D$. rotundus shelters were located, two of which were natural: a sandstone cave of Piramboia Formation Geology and Quartzarênic Neosol inhabited by only one bat, and another basaltic cave of Itaqueri Formation Geology and Red-yellow Latosol with an estimated population of 100 D. rotundus. $75 \%$ of the shelters were in pasture and sugarcane areas, followed by areas of native vegetation and riparian vegetation associated with pastures. The presence of D. rotundus shelters in sugarcane and pastoral areas in a greater quantity than in forest cover areas highlights the importance of offering artificial shelters in agricultural areas. The slope of the land on which the shelters were located ranged from $3 \%$ to $29 \%$. $62.5 \%$ of the shelters were in areas with low slopes with the presence of pastures, but close to areas with more rugged relief and native vegetation with altitudes ranging between $475 \mathrm{~m}$ and $929 \mathrm{~m}$. All shelters were located close to bodies of water. Although bodies of water do not appear as a factor of receptivity to the presence of shelters of D. rotundus in the epidemiological model indicated by the Herbivore Rabies Control Manual - MAPA, in the present study the proximity of all roosts of $D$. rotundus to water bodies highlights the importance of this factor in environmental receptivity to the presence of roosts for these bats, making it relevant to include this factor in epidemiological models for controlling rabies in herbivores. Thus, it is necessary to reassess the importance of factors of receptivity to the presence of D. rotundus roosts in epidemiological models, considering the scale and particularities of each region under study, the inclusion of other types of geological formation in addition to limestone for the formation of natural shelters, the inclusion of new types and land cover and the proximity of water bodies.
\end{abstract}

Keywords: Desmodus rotundus, rabies, receptivity, roosts

\section{ANÁLISIS CUANTITATIVO DE LA RECEPTIVIDAD DE LA PRESENCIA DE HEMATOPHAGUS BAT SHELTERS Desmodus rotundus EN EL MUNICIPIO DE SÃO PEDRO-SP}

\section{RESUMEN}

El murciélago vampiro Desmodus rotundus es el principal transmisor de la rabia herbívora, responsable de enormes pérdidas económicas en la ganadería en América Latina. Debido a las interacciones de $D$. rotundus con el medio ambiente, el riesgo de rabia en herbívoros puede explicarse por la vulnerabilidad y receptividad del medio ambiente a la capacidad del ecosistema para sustentar poblaciones de D. rotundus. Utilizando un Sistema de Información Geográfica, se analizaron cuantitativamente los siguientes determinantes de la receptividad en

Mialhe PJ, Moschini LE, Piga FG. Análise quantitativa da receptividade a presença de abrigos de morcegos hematófagos Desmodus rotundus no Município de São Pedro-SP. Vet. e Zootec. 2022 ; v29: 001-015. 
los que se encontraron los refugios de murciélagos vampiro D. rotundus en la ciudad de São Pedro - SP: tipo de suelo y geología, uso y cobertura del suelo, pendiente, hipsometría y proximidad a cuerpos de agua. Se ubicaron ocho refugios de D.rotundus, siendo dos refugios naturales: una cueva de arenisca de Geología de la Formación Piramboia y Quartzarênico Neosol habitada por un solo murciélago, y otra cueva basáltica de Geología de la Formación Itaqueri y Latosol Rojo-amarillo con una población estimada de 100 D. rotundus. El 75\% de los refugios estaban en áreas de pastos y caña de azúcar, seguidos de áreas de vegetación nativa y vegetación de ribera asociada a pastos. La presencia de refugios de D. rotundus en áreas cañeras y pastorales en mayor cantidad que en áreas de cobertura forestal resalta la importancia de ofrecer refugios artificiales en áreas agrícolas. La pendiente del terreno en el que se ubicaron los refugios osciló entre el 3\% y el 29\%. El 62,5\% de los refugios se encontraban en zonas de baja pendiente con presencia de pastos, pero próximas a zonas de relieve más accidentado y vegetación autóctona con altitudes que oscilan entre 475 my 929 m. Todos los refugios estaban ubicados cerca de cuerpos de agua. Si bien los cuerpos de agua no aparecen como factor de receptividad a la presencia de refugios de D. rotundus en el modelo epidemiológico indicado por el Manual de Combate a la Rabia de Herbívoros - MAPA, en el presente estudio la proximidad de todos los refugios de D. rotundus to bodies d'agua destaca la importancia de este factor en la receptividad ambiental a la presencia de refugios para estos murciélagos, por lo que es relevante incluir este factor en los modelos epidemiológicos para el control de la rabia en herbívoros. Así, es necesario reevaluar la importancia de los factores de receptividad a la presencia de refugios de D. rotundus en los modelos epidemiológicos, considerando la escala y particularidades de cada región en estudio, la inclusión de otros tipos de formación geológica además de la caliza para la formación de refugios naturales, inclusión de nuevos tipos y coberturas terrestres y proximidad de cuerpos de agua.

Palabras clave: Desmodus rotundus, ira, receptividad, refugio.

\section{INTRODUÇÃO}

A raiva é uma doença aguda do Sistema Nervoso Central (SNC) que pode acometer todos os mamíferos, inclusive os seres humanos. É caracterizada por uma encefalomielite fatal causada por vírus do gênero Lyssavirus , transmitida pela inoculação do vírus da raiva, contido na saliva de animais infectados, principalmente por meio de mordeduras, sendo uma das mais antigas doenças conhecidas (1).Em virtude de sua relevância para as áreas da saúde pública, da ecologia e da economia essa enfermidade tem sido estudada, no intuito de identificar as influências da alteração do meio ambiente na sua difusão e as áreas prioritárias para o seu controle (2).

O morcego vampiro Desmodus rotundus é a espécie mais comum e abundante de morcego hematófago, e devido as suas funções na transmissão da raiva para o gado e seres humanos na região Neotropical, tem recebido atenção especial das autoridades de saúde pública em toda América Latina $(3,4)$.

A raiva dos herbívoros domésticos é responsável por enormes prejuízos econômicos diretos na pecuária. Aproximadamente, 30 mil animais, entre herbívoros e suínos, foram a óbito entre 2000 e 2012 no Brasil, sendo 10.584 só na região Sudeste, com média de 814 óbitos confirmados para raiva anualmente (5).

As atividades antrópicas provocaram intensas mudanças na paisagem com a supressão da vegetação nativa, incremento da urbanização e do agronegócio (6). Estas mudanças têm importante impacto no equilíbrio ecológico e influência no movimento de morcegos em áreas rurais e silvestres (7).

Mialhe PJ, Moschini LE, Piga FG. Análise quantitativa da receptividade a presença de abrigos de morcegos hematófagos Desmodus rotundus no Município de São Pedro-SP. Vet. e Zootec. 2022 ; v29: 001-015. 
Entre 2002 e 2009 foram registrados casos de raiva em 1.163 morcegos: 80,0\% deles não hematófagos (933/1.163); e 20,0\% hematófagos (230/1.163). No mesmo período, o maior número de notificações de raiva ocorreu para os animais de produção, com 9.277 positivos: $88,0 \%$ bovinos (8.173/9.277); 10,0\% equinos (918/9.277); e 2,0\% (186/9.277), outros animais de produção (8).

A ocupação do espaço condiciona a forma de comportamento ecológico do transmissor, sendo que esse comportamento é dado pela disponibilidade de abrigo e alimento oferecidos (8). D. rotundus apresenta uma alta versatilidade na utilização de abrigos, podendo ser naturais, como grutas e ocos de árvore, ou artificiais, constituídos por casas abandonadas, pontes, bueiros, fornos de carvão etc. Caracterizam-se por apresentar elevado grau de umidade e ambientes escuros e frescos, o que é mais frequentemente encontrado em grutas naturais que só recebem sol pela parte da manhã (5).

$\mathrm{O}$ desmatamento frequente e a modificação do espaço silvestre reduzem o número de abrigos naturais dos morcegos hematófagos, o que induz à migração dessas espécies para áreas onde haja intensificação da produção pecuária ou próximas às cidades, podendo aumentar a exposição de populações humanas (9).

Estudo baseado no censo agropecuário e com dados agregados à malha municipal indicou que a raiva bovina no estado de Minas Gerais sofreu influências das transformações antrópicas no espaço agrário entre 1976 e 1997, especialmente do uso da terra. A enfermidade esteve associada às lavouras permanentes e temporárias, às pastagens naturais e plantadas e ao efetivo bovino (10).

O estado de São Paulo apresenta tipos de usos e cobertura da terra diferentes do início da sua ocupação. Houve diminuição do desmatamento e regeneração da mata em diversos municípios paulistas nos períodos entre 1990 e 2000 (11). Em uma parcela do estado, observou-se incremento paulatino das áreas de cana-de-açúcar (12) enquanto as manchas urbanas aumentaram consideravelmente nas regiões de São José dos Campos e Campinas na década de 90 (13). Essas constatações podem estar influenciando na dinâmica da distribuição da enfermidade há alguns anos.

Os mosaicos de uso e de cobertura da terra influenciaram a distribuição espacial da raiva bovina na região de maior incidência do estado de São Paulo. A enfermidade esteve fortemente moldada pelas áreas de vegetação rasteira (pastagens). O relevo pareceu formar os mosaicos de uso e cobertura da terra, os quais acabaram determinando os locais de grassamento ou não da enfermidade. Grandes áreas contínuas do mesmo tipo de uso e classe de cobertura da terra tenderam a ser protetoras da raiva bovina, ou favorecedoras em áreas vizinhas. Bovinos localizados em pequenas "ilhas" de pastagem entre as matrizes de vegetação de plantações extensivas e cana-de-açúcar poderiam receber proteção das regiões plantadas, desde que o raio de voo dos morcegos infectados fosse menor que a distância entre as "ilhas" (14).

Devido às interações de $D$. rotundus com o meio ambiente, o risco da raiva nos herbívoros pode ser explicado por dois componentes principais: receptividade e vulnerabilidade. Vulnerabilidade é um conjunto de fatores relacionados à capacidade de ingresso do transmissor numa área e à circulação viral. Receptividade é um conjunto de variáveis que expressam a capacidade de o ecossistema albergar populações de D. rotundus e estão relacionados à disponibilidade de alimento e de abrigos. Tais fatores possibilitam a difusão da doença para novas áreas e servem de facilitadores para que este processo ocorra $(5,15)$.

Os determinantes da receptividade estão relacionados à disponibilidade de alimento e de abrigos. O Manual de Combate a Raiva dos Herbívoros - MAPA (5) indica como 
determinante de receptividade ligado ao alimento a densidade de herbívoros domésticos/área útil de pastagem. Porém, a distância dos abrigos de D. rotundus aos rebanhos de herbívoros domésticos e o número de morcegos existentes nos abrigos parece ter maior relevância na definição de áreas de ataques a bovinos que a densidade populacional destes, visto que grandes populações de $D$. rotundus podem concentrar seu forrageamento a poucos quilômetros dos abrigos, independente da densidade populacional bovina existente nestas áreas (16).

Existem poucos estudos quantitativos dos determinantes de receptividade relacionados à disponibilidade de abrigos aptos para $D$. rotundus, sendo a maioria deles qualitativos. Este trabalho teve como objetivo analisar quantitativamente os determinantes de receptividade a presença de abrigos aptos de morcegos hematófagos $D$. rotundus no município de São Pedro - SP, utilizando de Sistema de Informações Geográficas.

\section{MATERIAIS E MÉTODOS}

O local de estudo foi o Município de São Pedro, localizado na região centro leste do estado de São Paulo, com uma área aproximada de 62.000 hectares e altitudes que variam entre as cotas 500 e 900 metros. A região serrana e nas encostas dos vales apresentam acentuada declividade, coberta por floresta nativa. Nos vales e regiões mais planas ocorrem a pecuária e culturas como cana-de-açúcar, eucalipto, laranja e pequenas lavouras de subsistência.

Durante o período de janeiro de 2001 a outubro de 2002 foram realizadas buscas por colônias de morcegos hematófagos em refúgios naturais e artificiais, seguindo as informações das entrevistas com proprietários e funcionários rurais. Quando localizados, foi avaliada a população de morcegos existentes através de contagem simples de indivíduos, presença de fezes frescas no local e quando encontrado colônias populosas contou-se a quantidade de morcegos aglomerados por metro quadrado e multiplicou-se pelo total da área ocupada por eles no abrigo.

Os abrigos foram georreferenciados com o uso de um receptor GPS modelo Garmim etrex e criado mapas temáticos relacionados a declividade, altitude, uso e cobertura do solo, utilizando-se cartas Topográficas na escala 1:50.000 do IBGE.

A produção de mapas temáticos foi realizada através do software ARCGIS 10.2.2. Para verificar se há áreas com solo calcário no município, foi pesquisado a geologia e o tipo de solo em que se encontravam os abrigos.

\section{RESULTADOS}

Foram encontrados um total de oito abrigos de D. rotundus, sendo $25 \%$ (2/8) grutas naturais, $12,5 \%(1 / 8)$ galeria de água e $62,5 \%$ (5/8) casas abandonadas. Somente no abrigo seis foram encontrados $D$. rotundus compartilhando o abrigo com outros morcegos não hematófagos. Os tipos de solos em que se encontravam os abrigos eram do tipo Neossolo Quartzarênico e Latossolo Vermelho-Amarelo, e a Geologia variou entre Formação Piramboia, Formação Itaqueri e Formação Serra Geral.

Os tipos de solos em que se encontravam os abrigos eram do tipo Neossolo Quartzarênico e Latossolo Vermelho-Amarelo, e a Geologia variou entre Formação Piramboia, Formação Itaqueri e Formação Serra Geral.

O tipo de abrigo, as referências geográficas, tipo de solo e geologia são mostrados na tabela 1 .

Mialhe PJ, Moschini LE, Piga FG. Análise quantitativa da receptividade a presença de abrigos de morcegos hematófagos Desmodus rotundus no Município de São Pedro-SP. Vet. e Zootec. 2022 ; v29: 001-015. 
A gruta de arenito (abrigo 3) localizada em neossolo quartzarênico com uma amplitude de aproximadamente $1,60 \mathrm{~m}$ de altura, $1,80 \mathrm{~m}$ de largura e $4 \mathrm{~m}$ de profundidade. A gruta localizada em latossolo vermelho-amarelo (abrigo 6) formada por vários matacões de granito com uma altura de 2,5m de altura, $2 \mathrm{~m}$ de largura e 18 metros de profundidade.

Todos abrigos estavam localizados a uma distância inferior a $3 \mathrm{~km}$ dos corpos d'agua, conforme mostrado na figura 1.

Os abrigos localizavam-se em solos ocupados por vegetação nativa, pastagem e canavial. O número de D. rotundus encontrados nos abrigos variou entre 1 a 200 . A declividade variou de $3 \%$ a $29 \%$, e a altitude variou entre $475 \mathrm{~m}$ a $929 \mathrm{~m}$. Na tabela 2 estão relacionadas as características como os tipos de uso do solo, número de D. rotundus encontrados, declividade e altitude dos abrigos de D. rotundus.

Tabela 1. Tipo de abrigo, referências geográficas, tipo de solo e geologia dos abrigos de $D$. rotundus no Município de São Pedro - SP.

\begin{tabular}{|c|c|c|c|c|c|}
\hline \multirow{2}{*}{$\begin{array}{l}\text { Número } \\
\text { do abrigo }\end{array}$} & \multirow[t]{2}{*}{ Tipo de abrigo } & \multicolumn{2}{|c|}{ UTM - 23s } & \multirow[t]{2}{*}{ Tipo de Solo } & \multirow[t]{2}{*}{ Geologia } \\
\hline & & $\mathrm{X}$ & $\mathrm{Y}$ & & \\
\hline 1 & (Galeria Água) & 804.525 & 7.500 .675 & Neossolo Quartzarênico & Formação Piramboia \\
\hline 2 & Casa abandonada & 807.930 & 7.505 .637 & Neossolo Quartzarênico & Formação Itaqueri \\
\hline 3 & Gruta arenito & 196.477 & 7.504 .165 & Neossolo Quartzarênico & Formação Piramboia \\
\hline 4 & Casa abandonada & 193.978 & 7.506 .686 & $\begin{array}{l}\text { Latossolo Vermelho- } \\
\text { Amarelo }\end{array}$ & Formação Itaqueri \\
\hline 5 & Casa abandonada & 198.959 & 7.508 .350 & Neossolo Quartzarênico & $\begin{array}{l}\text { Formação Serra } \\
\text { Geral }\end{array}$ \\
\hline 6 & Gruta basáltica & 198.440 & 7.507 .369 & $\begin{array}{l}\text { Latossolo Vermelho- } \\
\text { Amarelo }\end{array}$ & Formação Itaqueri \\
\hline 7 & Casa abandonada & 807.873 & 7.508 .612 & Neossolo Quartzarênico & Formação Piramboia \\
\hline 8 & Casa abandonada & 195.475 & 7.498 .267 & $\begin{array}{l}\text { Latossolo Vermelho- } \\
\text { Amarelo }\end{array}$ & Formação Itaqueri \\
\hline
\end{tabular}

Tabela 2. Tipo de uso do solo, declividade e altitude dos abrigos de D. rotundus no Município de São Pedro - SP.

\begin{tabular}{llccc}
\hline $\begin{array}{c}\text { Número } \\
\text { do abrigo }\end{array}$ & \multicolumn{1}{c}{ Tipo de Uso do Solo } & $\begin{array}{c}\text { Número de } D . \\
\text { rotundus }\end{array}$ & Declividade & Altitude \\
\hline 1 & Pastagem & 200 & $6 \%$ & $500 \mathrm{~m}$ \\
2 & Pastagem e cana de açúcar & 2 & $4 \%$ & $550 \mathrm{~m}$ \\
3 & Pastagem e vegetação ripária & 1 & $6 \%$ & $565 \mathrm{~m}$ \\
4 & Pastagem e cana de açúcar & 1 & $9 \%$ & $919 \mathrm{~m}$ \\
5 & Pastagem & 11 & $29 \%$ & $929 \mathrm{~m}$ \\
6 & Vegetação Nativa & 100 & $13 \%$ & $755 \mathrm{~m}$ \\
7 & Cana-de-açúcar & 4 & $3 \%$ & $919 \mathrm{~m}$ \\
\hline
\end{tabular}

Mialhe PJ, Moschini LE, Piga FG. Análise quantitativa da receptividade a presença de abrigos de morcegos hematófagos Desmodus rotundus no Município de São Pedro-SP. Vet. e Zootec. 2022 ; v29: 001-015. 


\begin{tabular}{lllll}
\hline 8 & Cana-de-açúcar & 1 & $15 \%$ & $548 \mathrm{~m}$
\end{tabular}

O mapa dos Usos e Cobertura do Solo no município de São Pedro - SP está representado na figura 1

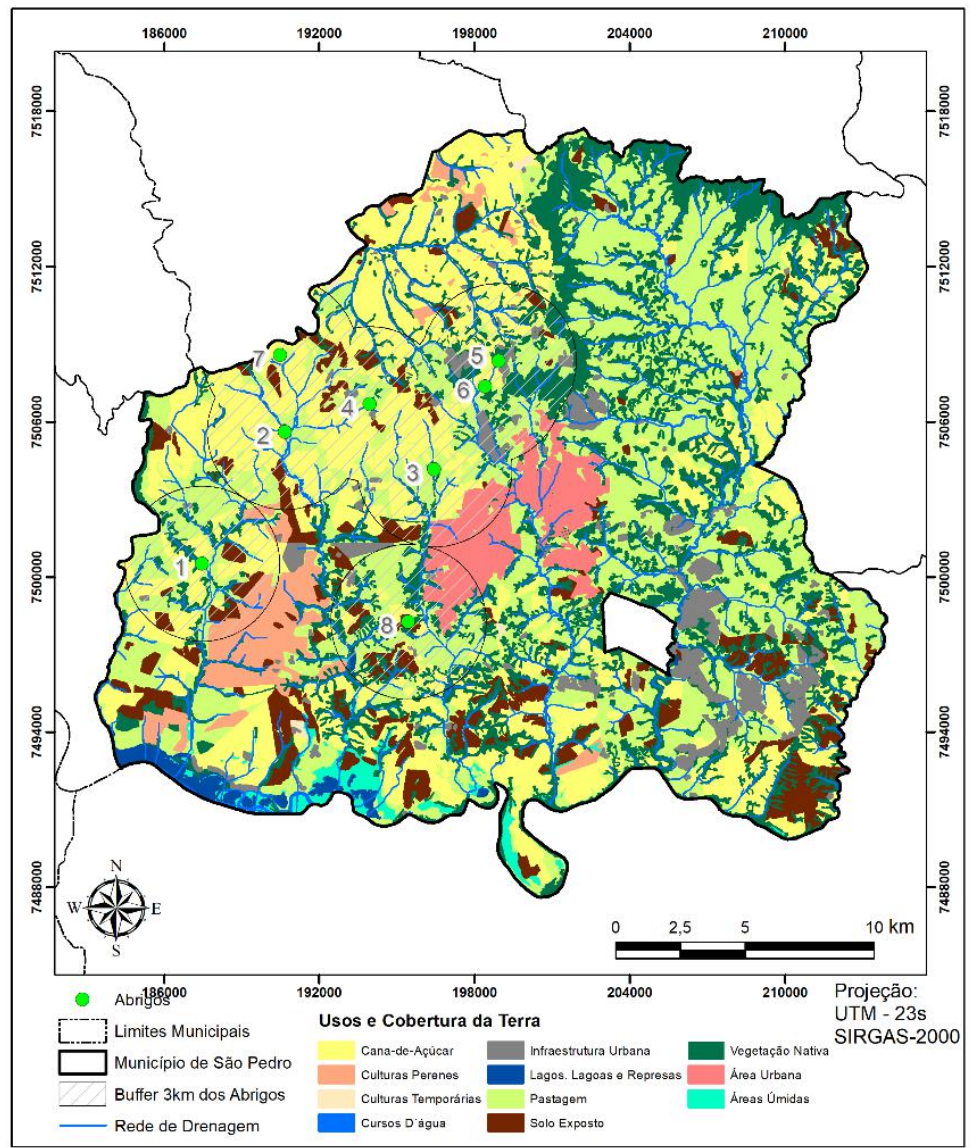

Figura 1. Uso e cobertura do solo no município de São Pedro - SP figura 2.

O percentual de áreas ocupadas por cada tipo de uso e cobertura do solo é mostrado na 


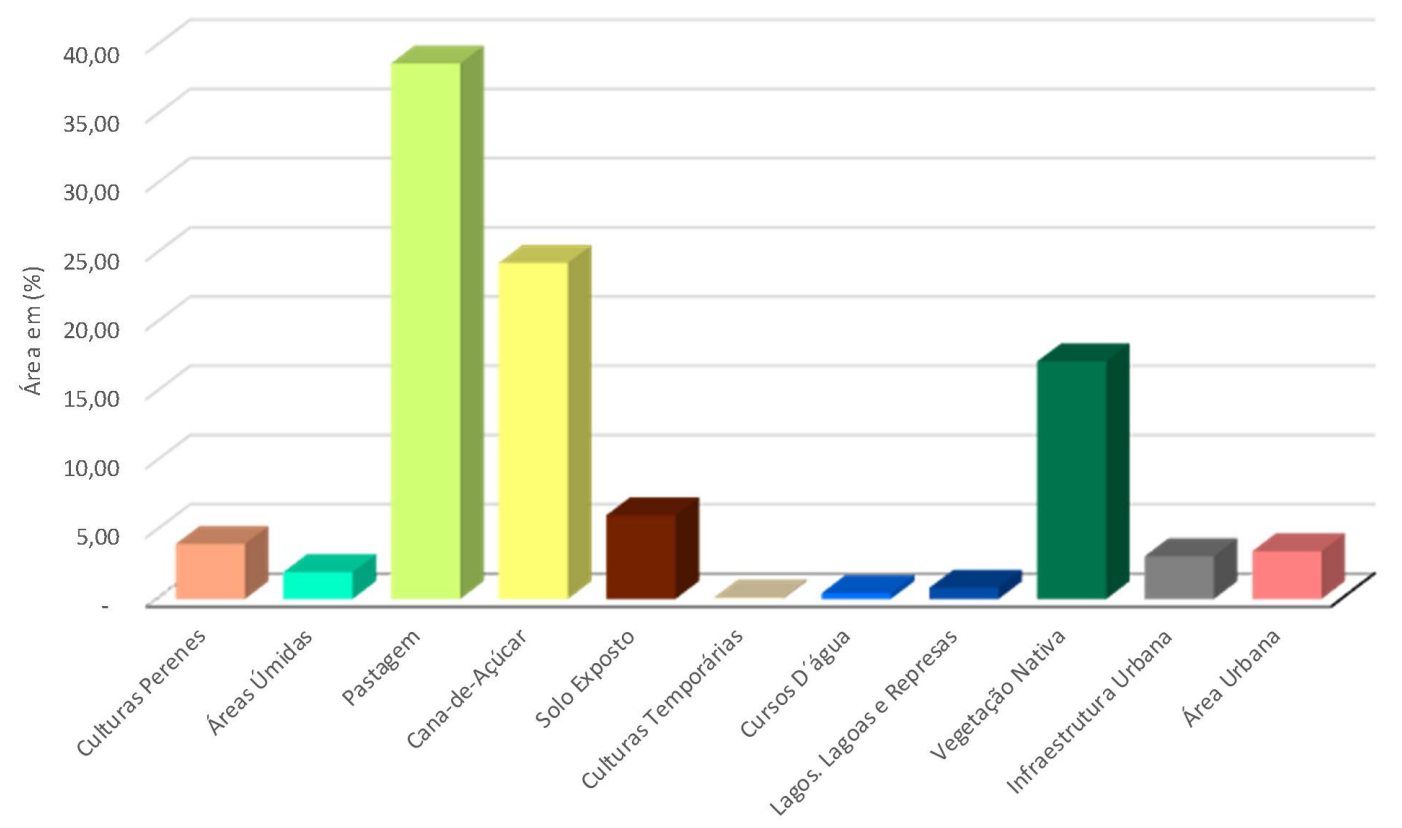

Figura 2. Áreas ocupadas por cada tipo de uso e cobertura do solo

A percentagem de abrigos de $D$. rotundus encontrados nas áreas ocupadas por diferentes tipos de solo e cobertura vegetal localizados no município de São Pedro é mostrado na Tabela 3.

Tabela 3. Tipo de uso do solo e percentagem de abrigos de D. rotundus localizados no Município de São Pedro - SP.

Uso do Solo e Cobertura Vegetal Percentagem de abrigos de D. rotundus localizados

Pastagem $25 \%$

Cana-de-açúcar $25 \%$

Pastagem e cana de açúcar $25 \%$

Pastagem e vegetação ripária $12,5 \%$

Vegetação Nativa $12,5 \%$

O mapa das Classes de Declividade com a localização dos abrigos de D. rotundus é representado na Figura 3. 


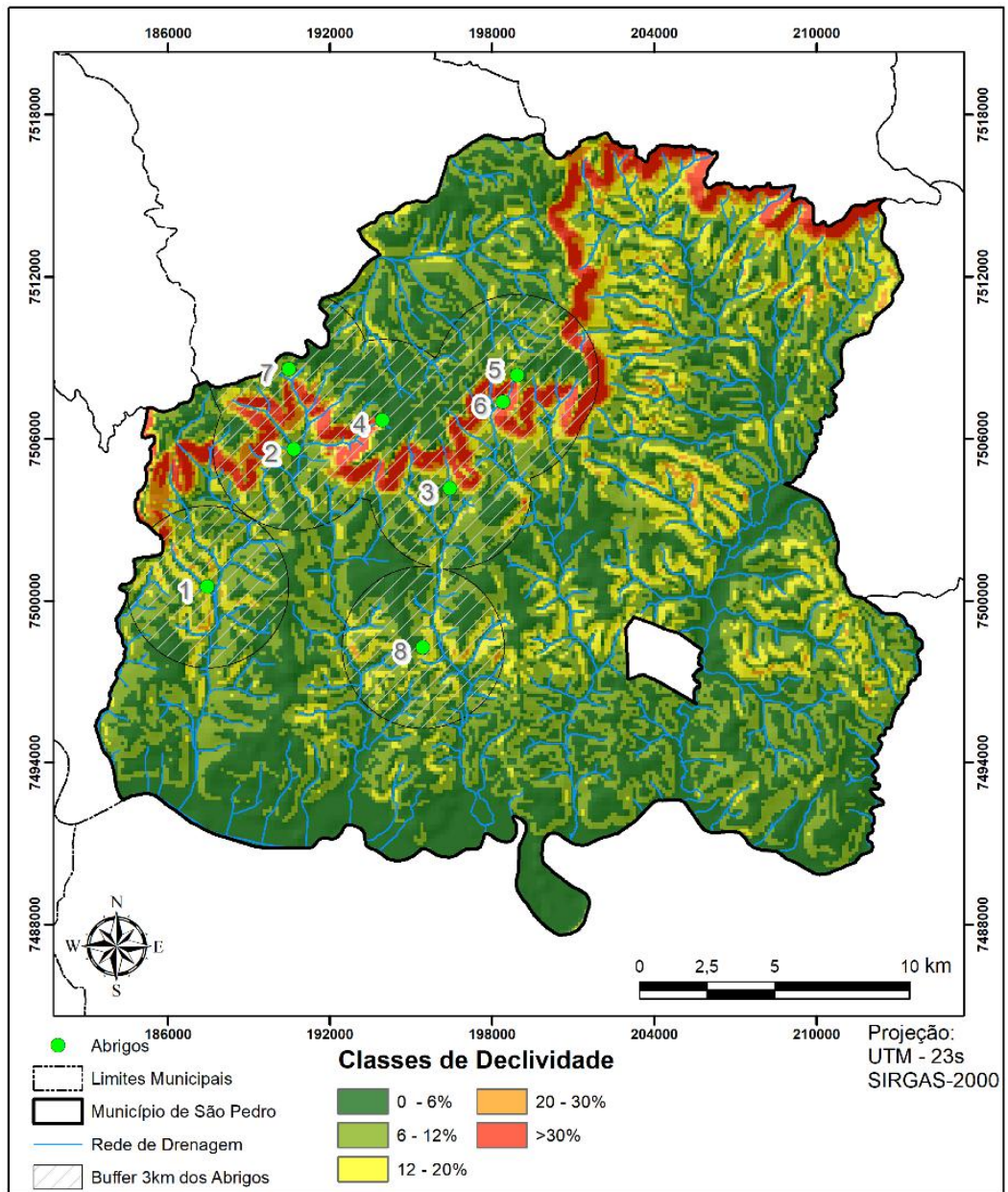

Figura 3. Mapa das Classes de Declividade com a localização dos abrigos de D. rotundus no Município de São Pedro.

O mapa Hipsométrico com a localização dos abrigos de $D$. rotundus é representado na figura 4 . 


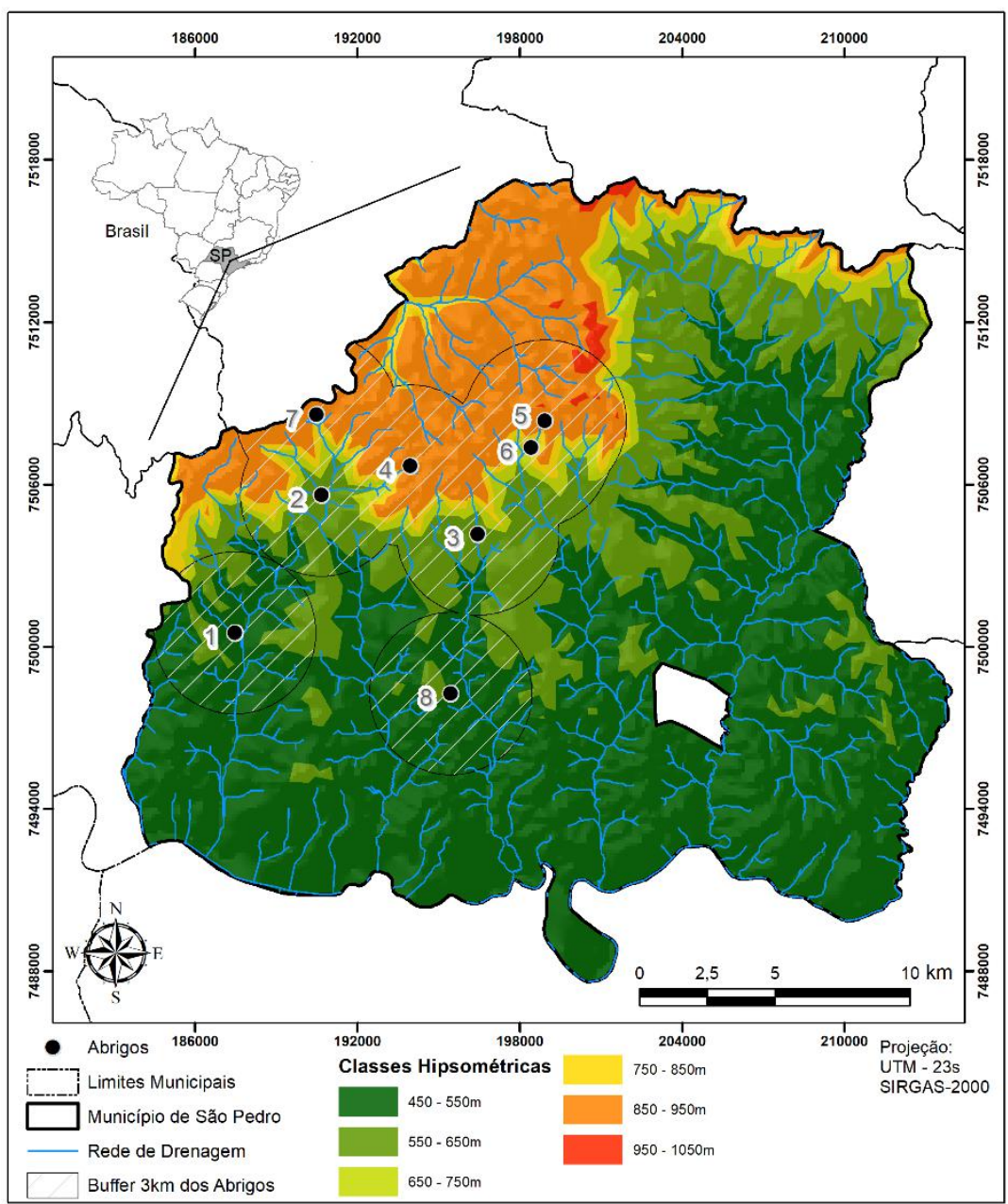

Figura 4. Mapa Hipsométrico com a localização dos abrigos de D. rotundus no Município de São Pedro.

Todos os outros abrigos estavam a uma distância inferior a $3 \mathrm{~km}$ dos principais corpos d'água da área de estudo, indicados nas Figuras 1, 3 e 4.

\section{DISCUSSÃO}

Em relação aos determinantes relacionados à disponibilidade de abrigos aptos para $D$. rotundus, o Manual de Combate a Raiva dos Herbívoros ${ }^{5}$ cita sete determinantes: 1Porcentagem de área com solo calcário, 2 - Porcentagem de área de matas permanentes 3 Declividade do terreno, 4 - Número e localização de abrigos naturais permanentes e temporários, 5- Quantidade de abrigos artificiais, 6 - Número de edificações com potencial utilização como abrigos para o transmissor, 7 - Altitude. A receptividade pode ser classificada em alta, média, baixa e nula, na dependência da presença e da intensidade com que os fatores supracitados se expressam, bem como da inter-relação entre eles.

A formação de grutas, as regiões cársticas, constituídas de rochas calcárias, sofrem a ação das águas superficiais e subterrâneas, cuja corrosão e abatimentos formam cavernas que garantem aos quirópteros, e em especial ao $D$. rotundus, refúgios que atendem plenamente aos requisitos de moradia (17). Estudos em algumas regiões do México e Cuba levaram à conclusão que cavernas de morcegos (cavernas eutróficas abrigando grandes e estáveis colônias de morcegos) são em grande parte representativa dos trópicos. No entanto, os dados recolhidos em todo o Brasil mostraram que as cavernas de morcegos são realmente uma exceção, geralmente restrito a áreas com alta densidade de cavernas. Este é o caso com 
cavernas de arenito, tais como aqueles no Pará e São Paulo $(18,19)$. Cavernas de calcário brasileiras raramente apresentam colónias muito grandes e estáveis. Pelo contrário, o número de indivíduos e espécies observadas em cada visita é variável, sugerindo a ocorrência de movimentos frequentes entre abrigos na área (20).

As cavernas de arenito brasileiras em geral abrigam grandes colónias de morcegos $(21,22)$. Para uma dada área, cavernas de arenito são geralmente muito menos abundantes do que os de calcário. De resto, a paisagem menos irregular em regiões de arenito é mais favorável à pecuária extensiva e agricultura (21).

Somente dois abrigos (25\%) de D. rotundus encontrados no Município de São Pedro foram categorizados como sendo naturais: uma gruta de arenito de Geologia Formação Piramboia e Neossolo Quartzarênico (abrigo três) e outra gruta natural basáltica de Geologia Formação Itaqueri e Latossolo Vermelho-amarelo (abrigo seis).

A gruta arenítica (abrigo três) possuí entrada única, de formato triangular, medido 1,60 $\mathrm{m}$ de altura por 1,80 $\mathrm{m}$ de largura, e alcançando uma profundidade de $4 \mathrm{~m}$. Em seu interior nascia uma fonte de água, que formava um lago com $1 \mathrm{~m}$ de profundidade e depois escoava como um pequeno córrego através da propriedade, e encontrava-se habitada por apenas um $D$. rotundus.

A gruta basáltica (abrigo seis) é constituída por vários matacões de granito sobrepostos que formam um abrigo de apenas uma entrada com aproximadamente $2.5 \mathrm{~m}$ de altura por $2 \mathrm{~m}$ de largura, e um comprimento de aproximadamente $18 \mathrm{~m}$. Nela habitava uma população estimada de $100 \mathrm{D}$. rotundus, que compartilhava o abrigo com outras espécies de morcegos não hematófagos.

Apesar do aparente contraste com outros estudos $(21,22)$ em que as cavernas de arenito brasileiras em geral abrigam grandes colônias de morcegos, tal diferença no presente estudo pode ser devida as maiores dimensões da gruta basáltica em relação a gruta arenítica, que possibilita melhores condições de colonização por uma maior população de morcegos.

Os percentuais de ocupação de abrigos naturais e artificiais por D. rotundus no município de São Pedro está relacionado à sua paisagem, pois apesar de possuir relevo mais acidentado ao norte que favorece a presença de abrigos naturais, a maior parte do município é composta por vales onde se pratica a pecuária, oferecendo grande número de construções rurais que podem ser utilizados como abrigos artificiais por D. rotundus (16). A ausência de sinais de $D$. rotundus em construções rurais e pontes localizadas nas proximidades dos pastos é um achado incomum, pois estes abrigos são amplamente utilizados por esses morcegos. A intensa movimentação de pessoas, animais e veículos nas proximidades dessas construções poderiam perturbar a permanência de $D$. rotundus nesses locais, preferindo colonizar locais mais protegidos (23).

A maior parte dos abrigos (62,5\%) estava localizada em áreas com a ocorrência de pastagens isoladas e áreas de pastagens combinadas com outros usos de solo (Tabela 3), indicando a importância da disponibilidade de alimento (herbívoros domésticos) na determinação da receptividade ambiental relacionado a presença de abrigos de $D$. rotundus. Assim, as populações de morcegos vampiros são favorecidas pela sua adaptabilidade a ambientes antropizados, e eles fazem especialmente bem em paisagens onde o gado e outros tipos de herbívoros domésticos são presentes em altas densidades para consumo humano (24).

Um quarto dos abrigos encontravam-se em áreas onde havia canaviais e se somados as áreas onde havia canaviais combinados com áreas de pastagem (Tabela 3) totalizam $50 \%$ das áreas em que foram encontrados abrigos de D. rotundus. Isto demonstra que a alta adaptabilidade de $D$. rotundus em colonizar abrigos artificiais em áreas cuja cobertura de solo é formada por lavoura extensiva $(14,25)$, como casas abandonadas (Tabela 1) que são comumente utilizadas para armazenamento de insumos e maquinários agrícolas.

Mialhe PJ, Moschini LE, Piga FG. Análise quantitativa da receptividade a presença de abrigos de morcegos hematófagos Desmodus rotundus no Município de São Pedro-SP. Vet. e Zootec. 2022 ; v29: 001-015. 
A agregação de áreas agrícolas e a combinação de diferentes tipos de cobertura do solo áreas adjacentes de um determinado local possuem efeito sobre a abundância de $D$. rotundus (26). A proximidade de grandes unidades dedicadas à pecuária para áreas dedicadas a atividades agrícolas pode ser considerada como um fator que favorece a presença do morcego vampiro.

Em relação à topografia, conforme ilustra a Tabela 4, a maior parte $(62,5 \%)$ das áreas onde se encontravam os abrigos de $D$. rotundus estavam em áreas com declividade inferior a $10 \%$, seguido de áreas com declividade entre 10 e 20\% (25\%) e o restante $(12,5 \%)$ dos abrigos estavam em áreas com uma declividade superior a $20 \%$, sendo a maior declividade encontrada foi de $29 \%$. Esses valores contrastam com os estudos de Braga (27), que estimou o ponto de corte da declividade do terreno em $42,1 \%$ para a ocorrência de abrigos naturais de $D$. rotundus no Brasil.

A diferença na escala de mapas do presente estudo e os trabalhos de Braga (27) pode ter sido uma das causas das diferenças na avaliação dos resultados obtidos. Este autor pode ter chegado a tal conclusão em função da menor escala em que foi efetuada a análise, utilizando o mapa internacional do milionésimo (escala 1:1.000.000) presente no site do IBGE 2002. O uso de escala menor oferece menor nível de detalhamento de informações geográficas, generalizam e agrupam as informações, enquanto uma escala maior permite, por sua vez, um maior nível de detalhamento das informações (28).

No estudo realizado no município de São Pedro foi utilizado uma escala menor (1: 50.000) que a utilizada por Braga (escala 1:1.000.000), portanto, pôde-se identificar detalhes mais específicos de uma determinada região, porém, em uma área consideravelmente menor.

Tabela 4. Percentagem de abrigos de D. rotundus localizados nas diferentes declividades no município de São Pedro - SP

\begin{tabular}{|c|c|}
\hline Declividade & Percentagem de abrigos localizados \\
\hline Menor que $10 \%$ & $62,5 \%$ \\
\hline Entre $10-20 \%$ & $25 \%$ \\
\hline Acima de $20 \%$ & $12,5 \%$ \\
\hline
\end{tabular}

A maioria dos abrigos estava em áreas com baixas declividades com presença de pastagens, porem próximos a áreas de relevo escarpado com a presença de vegetação nativa (Figura 3) do qual D. rotundus tem preferência (29), podendo assim abrigar outras colônias de morcegos que não foram localizadas.

Quanto à altitude, três abrigos (37,5\%) estavam abaixo de $650 \mathrm{~m}$, dois $(25 \%)$ a uma altitude entre $650-800 \mathrm{~m}$, e três $(37,5 \%)$ a uma altitude superior a $800 \mathrm{~m}$ (Tabela 2 e Tabela 5). Esses dados contrastam com os estudos na região centro sul e centro leste do estado de São Paulo (30), onde a maioria dos abrigos (57\%) estava entre $650-800 \mathrm{~m}$ e com os estudos no Vale do Paraíba localizado na região leste do estado de São Paulo, onde a maioria $(64,28 \%)$ dos abrigos estava em altitudes entre $550-650 \mathrm{~m}$.

Tabela 5. Percentagem de abrigos de D. rotundus localizados nas diferentes altitudes no município de São Pedro - SP

\begin{tabular}{lc}
\hline \multicolumn{1}{c}{ Altitude } & Percentagem de abrigos localizados \\
\hline Acima de $650 \mathrm{~m}$ & $37,5 \%$ \\
Entre $650-800 \mathrm{~m}$ & $25 \%$ \\
Superior a $800 \mathrm{~m}$ & $37,5 \%$ \\
\hline
\end{tabular}

Essa diferença pode ser explicada pelas diferentes condições topográficas das regiões oeste e leste do estado de São Paulo. A região oeste, assim como a noroeste está localizada

Mialhe PJ, Moschini LE, Piga FG. Análise quantitativa da receptividade a presença de abrigos de morcegos hematófagos Desmodus rotundus no Município de São Pedro-SP. Vet. e Zootec. 2022 ; v29: 001-015. 
no Planalto Ocidental, ao contrário do que se observa na região leste, caracterizada como região montanhosa, com topografia acidentada e áreas ainda cobertas pela Mata Atlântica, onde a quantidade de abrigos naturais ainda é abundante (31). Almeida et al. (17) em seus trabalhos na região cárstica de Cordisburgo - MG, 38,1\% dos abrigos encontrados estavam a uma altitude acima de $800 \mathrm{~m}$ (17), valor percentual este muito próximo ao encontrado nessa mesma altitude no município de São Pedro (37,5\%), podendo ser um indicador para formação de abrigos de $D$. rotundus em regiões de topografia elevada e acidentada.

Embora a presença de corpos d'agua não conste como fator de receptividade no modelo epidemiológico proposto no Manual de Controle da Raiva dos Herbivoros (5), no presente estudo todos os abrigos encontrados estavam a próximos a estes, corroborando outros Taddei et al. (31) que relatam que os principais rios do estado de São Paulo são as principais feições geográficas relacionadas à presença de $D$. rotundus, o que mostra a importância deste fator de receptividade para a presença de abrigos destes morcegos.

Desta forma faz-se necessária a inclusão de novos fatores de receptividade relacionados a presença de abrigos de $D$. rotundus. Apesar da importância do solo calcário para formação de áreas cársticas, deve-se considerar a inclusão de outros tipos de solo que possibilitem a formação de grutas e abrigos naturais de D. rotundus. Além das cavernas formadas por solo arenítico em áreas de pastagens, a presença de cavernas formadas em solo basáltico em áreas de vegetação nativa também pode possuir abrigos naturais de grandes dimensões capazes de abrigar uma grande população de $D$. rotundus, como encontrado no abrigo seis no município de São Pedro.

A topografia está relacionada com uso da terra e receptividade ambiental à presença de abrigos de morcegos hematófagos. Regiões escarpadas costumam estar cobertas por mata nativa, assim como as regiões com corpos d'agua e mata ciliar. Regiões de topografia menos acentuadas estão mais relacionadas as áreas de pastagens e culturas agrícolas. Ambas favorecem a presença de abrigos de $D$. rotundus, sendo as primeiras com oferta de abrigos naturais e água, e a segunda com oferta de abrigos artificiais e alimento (14).

Desta forma faz-se necessária uma reavaliação da importância dos fatores de receptividade à presença de abrigos de D. rotundus nos modelos epidemiológicos, considerando a escala e particularidades de cada região em estudo, a inclusão de novos tipos e cobertura de solo e proximidade de corpos d'agua.

\section{CONCLUSÃO}

A maior ocupação do solo no município de São Pedro por pastagens e a presença da maioria dos abrigos de D. rotundus nestas áreas, evidencia a oferta de abrigos artificiais (construções rurais abandonadas) e naturais (grutas de arenito) em áreas de pastagens. A presença de abrigos de D. rotundus em áreas de lavoura em quantidade superior a áreas de cobertura florestal ressalta a importância dos abrigos artificiais em áreas agrícolas.

Apesar de corpos d'agua não constarem como fator de receptividade à presença de abrigos de $D$. rotundus no modelo epidemiológico indicado pelo Manual de Combate a Raiva dos Herbívoros - MAPA, no presente estudo a proximidade de todos os abrigos de $D$. rotundus a corpos d'agua evidencia a importância deste fator na receptividade ambiental à presença de abrigos destes morcegos, tornando relevante a inclusão deste fator nos modelos epidemiológicos de controle a raiva dos herbívoros.

\section{REFERÊNCIAS}

1. Brasil. Ministério da Saúde. Secretaria de Vigilância em Saúde. Departamento de Vigilância Epidemiológica. Manual de diagnóstico laboratorial da raiva [Internet]. Brasília:

Mialhe PJ, Moschini LE, Piga FG. Análise quantitativa da receptividade a presença de abrigos de morcegos hematófagos Desmodus rotundus no Município de São Pedro-SP. Vet. e Zootec. 2022 ; v29: 001-015. 
Ministério da Saúde; 2008 [citado 18 Nov 2021]. Disponível em: https://bvsms.saude.gov.br/bvs/publicacoes/manual_diagnostico_laboratorial_raiva.pdf

2. Gomes MN, Monteiro AMV, Nogueira VS, Gonçalves CA. Áreas propícias para o ataque de morcegos hematófagos Desmodus rotundus em bovinos na região de São João da Boa Vista, estado de São Paulo. Pesqui Vet Bras [Internet]. 2007 [citado 18 Nov 2021];27(7):307-13. Disponível em: http://www.scielo.br/pdf/pvb/v27n7/a09v27n7.pdf

3. Lee DN, Papes M, Den Bussche RAV. Present and potential future distribution of common vampire bats in the Americas and the associated risk to cattle. PLoS One. 2012;7(8):e4266. doi: https://doi.org/10.1371/journal.pone.0042466.

4. Vigilato M, Cosivi O, Knöbl, T, Clavijo A, Silva H. Rabies update for Latin America and the Caribbean. Emerg Infect Dis [Internet]. 2013 [citado 18 Nov 2021];19(4):678-679. Disponível em: https://wwwnc.cdc.gov/eid/article/19/4/12-1482_article

5. Brasil. Ministério da Agricultura, Pecuária e Abastecimento. Controle da raiva dos herbívoros: manual técnico. Brasília: MAPA; 2009 [citado 18 Nov 2021]. p. 43-56. Disponível em: https:/www.gov.br/agricultura/pt-br/assuntos/sanidade-animal-evegetal/saude-animal/programas-de-saude-animal/raiva-dos-herbivoros-eeeb/MANUAL_RAIVAHERBVOROS2009.pdf

6. Ferrari JJF, Barros MA, Gomes MN, Souza CAM, Oliveira RN, Cruz FPN, et al. Análise da mudança da cobertura e uso da terra dos municípios de Jacareí e Santa Branca-SP como subsídio ao estudo das ocorrências de raiva transmitida por morcegos. Soc Nat [Internet]. 2011 [citado 18 Nov 2021];23(2):211-26. Disponível em: http://www.scielo.br/j/sn/a/9YhCcD5Vx5hnPGBGRrk7vTq/?lang=pt

7. Constantine DG. Geographic translocation of bats: knows and potential problems. Emerg Infect Dis [Internet]. 2003 [citado 18 Nov 2021];9(1):17-21. Disponível em: https://www.ncbi.nlm.nih.gov/pmc/articles/PMC2873759/pdf/02-0104.pdf

8. Wada MY, Manrique Rocha S, Maia-Elkhoury ANS. Situação da Raiva no Brasil, 2000 a 2009. Epidemiol Serv Saude [Internet]. 2011 [citado 18 Nov 2021];20(4):509-18. Disponível em: http://scielo.iec.gov.br/scielo.php?script=sci_arttext\&pid=S167949742011000400010

9. Reis NR, Peracchi AL, Pedro WA, Lima IP, editores. Morcegos do Brasil [Internet]. Londrina: Nélio R. dos Reis; 2007 [citado 18 Nov 2021]. Disponível em: http://www.uel.br/pos/biologicas/pages/arquivos/pdf/Morcegos_do_Brasil.pdf

10. Silva JA, Moreira EC, Haddad JPA, Sampaio IBM, Modena CM, Tubaldini MAS. Uso da terra como determinante da distribuição da raiva bovina em Minas Gerais, Brasil. Arq Bras Med. Vet Zootec. 2001;53(3):273-283. doi: http://dx.doi.org/10.1590/S010209352001000300002.

11. Ehlers EM. Determinantes da recuperação da Mata Atlântica no estado de São Paulo [tese] [Internet]. São Paulo: Universidade de São Paulo; 2003 [citado 18 Nov 2021]. Disponível em: http://www.teses.usp.br/teses/disponiveis/90/90131/tde-28022008-170551/en.php

Mialhe PJ, Moschini LE, Piga FG. Análise quantitativa da receptividade a presença de abrigos de morcegos hematófagos Desmodus rotundus no Município de São Pedro-SP. Vet. e Zootec. 2022 ; v29: 001-015. 
12. Rudorff BFT, Berka LMS, Xavier AC, Moreira MA, Duarte V, Rosa VGC, et al. Estimativa de área plantada com cana-de-açúcar em municípios do estado de São Paulo por meio de imagens de satélites e técnicas de geoprocessamento: ano safra 2003/2004. São José dos Campos: INPE; 2004 [citado 18 Nov 2021]. Disponível em: http://mtcm12.sid.inpe.br/col/sid.inpe.br/sergio/2004/07.02.14.36/doc/publicacao.pdf

13. Pereira NM, Correia VRM. Uso de imagens de satélite como subsídio ao estudo do processo de urbanização. São José dos Campos: INPE; 2005 [citado 18 Nov 2021]. Disponível em: http://urlib.net/rep/sid.inpe.br/iris@1912/2005/09.29.12.22

14. Gomes MN, Monteiro AMV, Escada MIS. Raiva bovina segundo os mosaicos de uso e cobertura da terra no estado de São Paulo entre 1992 e 2003. Arq Bras Med Vet Zootec. 2011;63(2):287-295. doi: http://dx.doi.org/10.1590/S0102-09352011000200003.

15. Dias RA, Nogueira Filho VS, Goulart CS, Telles ICO, Marques GHF, Ferreira F, et al. Modelo de risco para circulação do vírus da raiva em herbívoros no Estado de São Paulo, Brasil. Rev Panam Salud Publica. 2011 [citado 18 Nov 2021];30(4):370-6. Disponível em: https://www.scielosp.org/article/rpsp/2011.v30n4/370-376/

16. Mialhe PJ, Moschini LE. Controle populacional do morcego hematófago Desmodus rotundus e redução de ataques a herbívoros domésticos no Município de São Pedro, São Paulo, Brasil. Fronteiras J Soc Technol Environ Sci. 2016;5(3):238-51. doi: https://doi.org/10.21664/2238-8869.2016v5i3.p238-251.

17. Almeida EO, Moreira EC, Naveda LAB, Herrmann GP. Combate ao Desmodus rotundus rotundus (E.Geoffroy, 1810) na região cárstica de Cordisburgo e Curvelo, Minas Gerais. Arq Bras Med Vet Zootec. 2002;54(2):117-26. doi: http://dx.doi.org/10.1590/S010209352002000200002.

18. Trajano E, Moreira JRA. Estudo da fauna de cavernas da Província Espeleológica Arenítica Altamira- Itaituba, Pará. Rev Bras Biol [Internet]. 1991 [citado 18 Nov 2021];51(1):13-29. Disponível em: https://dspace.icmbio.gov.br/jspui/handle/cecav/767

19. Campanha RAC, Fowler HG. Roosting assemblages of bats in arenitic caves in remnant fragments of Atlantic Forest in southeastern Brazil. Biotropica. 1993;25(3):362-365 doi: https://doi.org/10.2307/2388798.

20. Trajano E. Movements of cave bats in Southeastern Brazil, with emphasis on the population ecology of the common vampire bat, Desmodus rotundus (Chiroptera). Biotropica [Internet]. 1996 [citado 18 Nov 2021];28(1):121-9. Disponível em: http://www.jstor.org/stable/2388777

21. Trajano E. Ecologia de populações de morcegos cavernícolas em uma região cárstica do Sudeste do Brasil. Rev Bras Zool. 1984;2(5):255-320. doi: http://dx.doi.org/10.1590/S0101-81751984000100001.

22. Trajano E. Fauna cavernícola brasileira: composição e caracterização preliminar. Rev Bras Zool. 1987;3(8):533-61. doi: http://dx.doi.org/10.1590/S0101-81751986000400004.

Mialhe PJ, Moschini LE, Piga FG. Análise quantitativa da receptividade a presença de abrigos de morcegos hematófagos Desmodus rotundus no Município de São Pedro-SP. Vet. e Zootec. 2022 ; v29: 001-015. 
23. Mialhe PJ. Characterization of Desmodus rotundus (E. Geoffroy, 1810) (Chiroptera, Phyllostomidae) shelters in the Municipality of São Pedro - SP. Braz J Biol. 2013;73(3):521-526. doi: https://doi.org/10.1590/S1519-69842013000300009

24. Bobrowiec PED, Lemes MR, Gribel R. Prey preference of the common vampire bat (Desmodus rotundus, Chiroptera) using molecular analysis. J Mammal [Internet]. 2015 [citado 18 Nov 2021];96(1):54-63. Disponível em: https://academic.oup.com/jmammal/article/96/1/54/862973

25. Silva JA, Moreira EC, Haddad JPA, Sampaio IBM, Modena CM, Tubaldini MAS. Uso da terra como determinante da distribuição da raiva bovina em Minas Gerais, Brasil. Arq Bras Med Vet Zootec. 2001;53(3):273-83. doi: http://dx.doi.org/10.1590/S010209352001000300002.

26. Bolivar-Cimé B, Flores-Peredo R, García-Ortíz AS, Murrieta-Galindo R, Laborde J. Influência de la estructura del paisaje en la abundancia de Desmodus rotundus (Geoffroy 1810) en el noreste de Yucatán, México. Ecosistemas Recur Agropecu. 2019 [citado 18 Nov 2021];6(17):263-271. Disponível em: http://www.scielo.org.mx/scielo.php?pid=S200790282019000200263\&script=sci_abstract

27. Braga GB. Modelo preditivo do risco de ocorrência da raiva em bovinos no Brasil [tese] [Internet]. São Paulo: Faculdade de Medicina Veterinária e Zootecnia, Universidade de São Paulo; 2014 [citado 18 Nov 2021]. Disponível em: http://www.teses.usp.br/teses/disponiveis/10/10134/tde-07012015-140605/pt-br.php

28. Dos Santos RF. Planejamento ambiental: teoria e pratica. São Paulo: Editora Oficina de Textos; 2004.

29. Acha PN, Málaga-Alba M. Economic losses due to Desmodus rotundus. In: Greenhall AM, Schmidt U, editors. Natural history of vampire bats. Florida: CRC Press; 1988. p. 208-13.

30. Rocha FA. Abrigos diurnos, agrupamentos e lesões corporais no morcego hematófago Desmodus rotundus (Chiroptera, Phyllostomidae) do Estado de São Paulo [dissertação] [Internet]. Botucatu: Universidade Estadual Paulista Júlio de Mesquita Filho; 2005 [citado 18 Nov 2021]. Disponível em: https://repositorio.unesp.br/handle/11449/98351

31. Taddei AV; Coordenadoria de Assistência Técnica Integral. Distribuição do morcego vampiro Desmodus rotundus no estado de São Paulo e a raiva dos animais domésticos [Internet]. Campinas: CATI; 1991 [citado 18 Nov 2021]. Disponível em: https://www.worldcat.org/title/distribuicao-do-morcego-vampiro-desmodus-rotunduschiroptera-phyllostomidae-no-estado-de-sao-paulo-e-a-raiva-dos-animaisdomesticos/oclc/27652080

Recebido em: 20/10/2021 Aceito em: 20/12/2021 